\title{
THE APPLICATION OF OPEN-SOURCE AND FREE PHOTOGRAMMETRIC SOFTWARE FOR THE PURPOSES OF CULTURAL HERITAGE DOCUMENTATION
}

\author{
Karol Bartoš, Katarína Pukanská, Janka Sabová, Gabriel Weiss ${ }^{1}$ \\ ${ }^{I}$ The Institute of Geodesy, Cartography and GIS, Faculty of BERG, The Technical University of \\ Košice, Letná9, 04200 Košice; karol.bartos@tuke.sk, katarina.pukanska@tuke.sk, \\ janka.sabova@tuke.sk,gabriel.weiss@tuke.sk
}

\begin{abstract}
The documentation of cultural heritage is an essential part of appropriate care of historical monuments, representing a part of our history. At present, it represents the current issue, for which considerable funds are being spent, as well as for the documentation of immovable historical monuments in a form of castle ruins, among the others. Non-contact surveying technologies - terrestrial laser scanning and digital photogrammetry belong to the most commonly used technologies, by which suitable documentation can be obtained, however their use may be very costly. In recent years, various types of software products and web services based on the SfM (or MVS) method and developed as open-source software, or as a freely available and free service, relying on the basic principles of photogrammetry and computer vision, have started to get into the spotlight. By using the services and software, acquired digital images of a given object can be processed into a point cloud, serving directly as a final output or as a basis for further processing. The aim of this paper, based on images of various objects of the Slanec castle ruins obtained by the DSLR Pentax K5, is to assess the suitability of different types of open-source and free software and free web services and their reliability in terms of surface reconstruction and photo-texture quality for the purposes of castle ruins documentation.
\end{abstract}

\section{INTRODUCTION}

Slovakia is a country with rich history and culture as many historical monuments like different historical buildings, castles, chateaus, archaeological sites, areas, findings and other movable and immovable monuments are situated there. Such objects are part of the cultural heritage of each country so it is necessary to protect them in a certain way, take care of and preserve them for future generations. And just for these purposes, it is necessary to document our cultural heritage in an appropriate way. In today's world full of technology, there are several possibilities to obtain such results. At present, mainly two technologies can be considered as the most advanced and suitable for the documentation of cultural heritage - laser scanning and digital photogrammetry.

Each of these technologies has its advantages and disadvantages (regarding the resulting accuracy for various distances of scanning vs. imaging, mobility, radiometric and geometric resolution, or purchase cost). At present, a number of requirements - mainly high accuracy, level of detail, complexity and reliability of data that in turn must have geometric and visual quality with effective collection and low volume, are imposed on the resulting data obtained by any of these technologies. Just achieving a low purchase cost while acquiring reliable results, which will meet the above requirements, is one of the major trends in the 3D surface reconstruction, computer modelling and documentation of cultural heritage (Kersten, 2012). The latest technologies and methods of laser scanning and digital photogrammetry meet these requirements to a large extent, but the purchase cost of hardware and software may be still too high in some cases.

Therefore, a lot of effort has been made for the development of new methods in computer vision for computer modelling from photographic images, reconstruction and display of 3D models. Based on this, various algorithms and software applications dealing with surface and object reconstruction from images began to emerge.

\section{OPEN-SOURCE AND FREE PHOTOGRAMMETRIC SOFTWARE}

The SfM method (Structure from Motion), which involves the simultaneous determination of interior and exterior orientation parameters and reconstruction of 3D structure captured on images, or MVS (Multi-View Stereo) representing an algorithm for image matching between a set of multiple image stereo pairs, are two main principles upon which those pieces of software operate. In the past, algorithms for surface reconstruction based on these principles were useful mainly for visualisation purposes and not for photogrammetry and mapping. But nowadays, thanks to technological advances, a large number of images may be automatically oriented within an arbitrary defined coordinate system using various algorithms. 
Currently, there are already several various software programs using the above principles, some of them being available for several years (a detailed procedure for solving the problem of fully automated, accurate and reliable matching between a set of multiple images was introduced as early as 1988 (Gruen - Baltsavias, 1988)), which are progressively being improved and also give rise to other new software tools. Among the best known, we can include the SIFT algorithm (Lowe, 2004) for obtaining distinctive invariant features from images which can be further used for reliable matching between these images, the system for generating 3D digital models from images (Pollefeys, 2004), the software MicMac (Pierrot-Deseilligny, 2006), the SfM system Bundler (Snavely 2010), the PMVS2 software for generating dense point clouds and CMVS for splitting very large files of images into smaller clusters (Furukawa, 2010), the CMPMVS software for reconstruction of textured MESH models from input images and parameters of interior and exterior orientation of a camera (Jancosek, 2011), or the GUI application VisualSFM for 3D reconstruction of objects from images using the SfM method (Wu, 2012) and others.

With the progressive expansion of internet, also various web services and applications began to appear in addition to the software tools, providing the possibility of generating point clouds or directly 3D MESH models from images, often without the need of installation of additional software applications on a computer of the end user. Currently, there are a number of them, for example 123D Catch by Autodesk, Photosynth by Microsoft, My3DScanner, ARC3D and more. However, for some of these services (e.g. Photosynth, My3DScanner) a fully automated approach is a big disadvantage, since they provide no possibility of user intervention in the reconstruction process, no information on the accuracy of calibration, orientation of images and the final model, nor any tools for data transformation into a coordinate reference system. As a result, such services are becoming unusable for creating sufficiently accurate and quality documentation.

It is therefore evident that nowadays there are several possibilities for image processing into a form of point cloud and subsequent digital 3D models, whether for documentation of immovable cultural heritage, archaeological artefacts, or completely different usage. However, it is questionable if such open-source and free software solutions are appropriate, of sufficient quality and highly accurate for image processing and generating outputs suitable for documentation of cultural heritage.

\section{SOFTWARE SELECTION}

Based on the analysis and image processing method, the following three pieces of open-source and free software of the various types were selected as the most suitable:

- VisualSFM - open-source software (Fig. 1),

- OSM-Bundler (Bundler + CMVS/PMVS2) - open-source software,

- Photosynth Toolkit (Photosynth (Fig. 1) + CMVS/PMVS2) - web service + open-source software.

VisualSFM (Wu, 2012) is basically a GUI application for 3D reconstruction of objects from images using the $S f M$ system into a point cloud. It is an upgraded version of author's previous projects supplemented with siftGPU and Multicore Bundle Adjustment algorithms. Moreover, this software provides an interface to run external tools like $P M V S / C M V S$, or it can prepare data for the $C M P-M V S$ software.

OSM-Bundler includes a set of open-source tools that allow to process 3D reconstruction of objects from images, using the Python programming language.

The key tools of this system are as follows:

- Bundler - SfM system for calibration, bundle adjustment and sparse cloud reconstruction (Snavely, 2012);

- $\quad$ PMVS2 - generating a dense point cloud (Furukawa, 2010, Furukawa - Ponce, 2010);

- $\quad C M V S$ - splitting images into clusters for rational use of computer memory, particularly for a larger set of images (Furukawa, 2010).

In the last case (Photosynth Toolkit), it is a combination of the web service Photosynth and the opensource software CMVS/PMVS2. Based on a set of overlapping images of an object, Photosynth performs calibration, orientation of images in space and reconstruction of a given object or scene into a sparse point cloud. Subsequently, the PMVS/CMVS software is used to its expansion, densification and filtration into a final point cloud. 

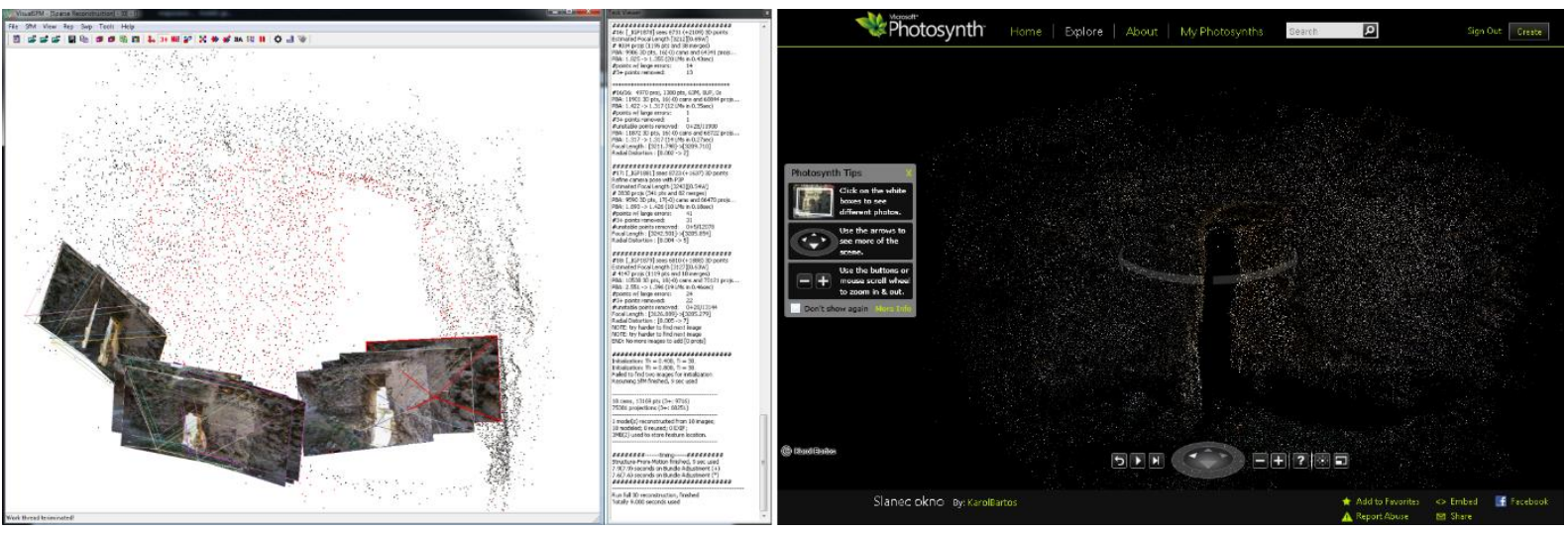

Fig. 1 Left - VisualSFM - workplace; right - Microsoft Photosynth web service

\section{IMAGING METHODOLOGY}

The following objects, parts of a cultural heritage monument - the Slanec castle (Fig. 2), were chosen for the purposes of comparison of selected photogrammetric software solutions in terms of their reliability, surface reconstruction quality and photo-texture quality (Bartoš, 2013):

- a wall of the Gothic palace,

- the southern part of the Nebojsa tower (donjon),

- the inner part of a tower window on the $3^{\text {rd }}$ floor.

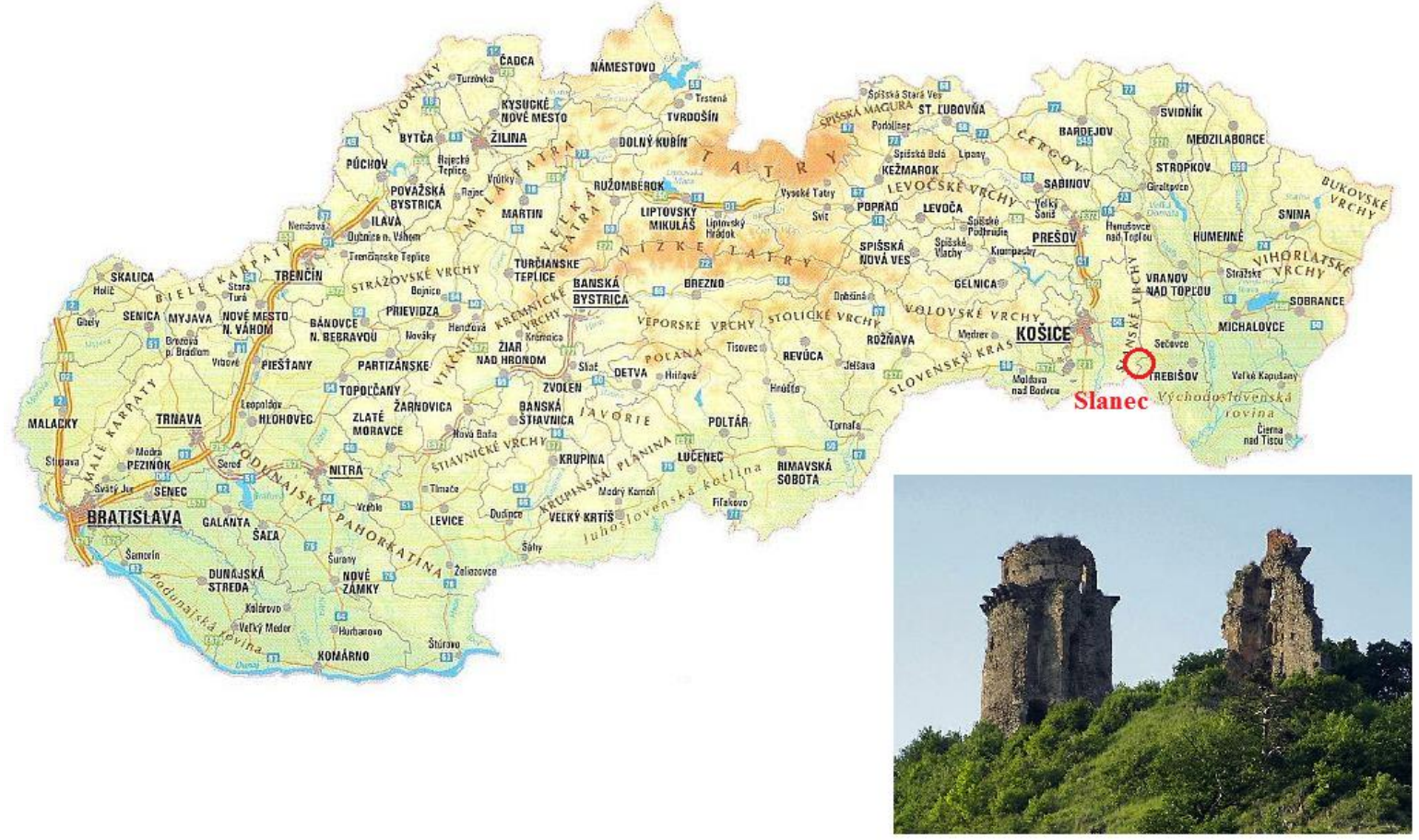

Fig. 2: The Slanec castle and its location in the Slovak Republic

All images were acquired by the DSLR camera Pentax $K-5$ with the SMC Pentax DA 4/15mm ED AL Limited lens, while the calibration of the digital camera was performed individually for each set of images of individual objects. For the PM Scanner 2012 software, it is represented by the „Full Field Calibration“. For the tested software, the parameters of interior orientation are determined during the processing individually for each used image (VisualSFM allows the use of fixed calibration for all images in the project) where each of the software solutions determines values of a focal length and two parameters of radial distortion.

12-bit coded targets, whose spatial coordinates were determined within the geodetic survey of this cultural heritage monument (Pukanská et al. 2012, Labant et al. 2012, Sabo - Bálint, 2013), were used as ground control points for the transformation of final point clouds into the national coordinate system S-JTSK (Datum of 
Uniform Trigonometric Cadastral Network). The results of this survey, in a form of output from the commercial PMSC 2012 software obtained by the method of optical scanning, were used as the reference data for the purpose of comparison of outputs from individual tested software methods.

Each of the software methods provides certain setup options of the basic parameters affecting the quality of the final reconstruction (a size of the correlation window; texture type; raster density; image resampling during processing; a number of images, in which the particular point is visible so its spatial position can be reconstructed). However, these options are not exactly the same in the case of the tested software and PM SC 2012. In order to achieve comparable results, the same values of parameters common to all of the software methods were set.

Parameters of imaging and subsequent image processing are given in Tab. 1.

Tab. 1 Parameters of imaging and image processing

\begin{tabular}{|c|c|c|c|c|c|c|c|}
\hline & $\begin{array}{c}\text { Number } \\
\text { of } \\
\text { images }\end{array}$ & $\begin{array}{l}\text { imaging } \\
\text { distance }\end{array}$ & $\mathrm{GCP}^{l}$ & $\mathrm{GSD}^{2}$ & $\begin{array}{l}\text { Number of } \\
\text { reconstructed points }\end{array}$ & $\begin{array}{l}\mathrm{m}_{X Y Z}{ }^{3} \\
{[\mathrm{~mm}]}\end{array}$ & \\
\hline \multirow{4}{*}{ 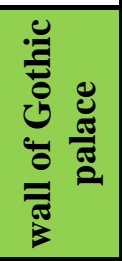 } & \multirow{4}{*}{50} & \multirow{4}{*}{$5-15 m$} & \multirow{4}{*}{6} & \multirow{4}{*}{$3 \mathrm{~mm}$} & 1234000 & 8,3 & PM Scanner \\
\hline & & & & & 2056000 & 3,9 & VisualSFM \\
\hline & & & & & 1403000 & 4,2 & OSM-Bundler \\
\hline & & & & & 1861000 & 5,0 & Photosynth Toolkit \\
\hline \multirow{4}{*}{ 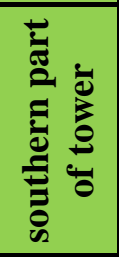 } & \multirow{4}{*}{20} & \multirow{4}{*}{$10-13 m$} & \multirow{4}{*}{5} & \multirow{4}{*}{$3 \mathrm{~mm}$} & 1699000 & 6,5 & PM Scanner \\
\hline & & & & & 1580000 & 0,6 & VisualSFM \\
\hline & & & & & 1515000 & 1,0 & OSM-Bundler \\
\hline & & & & & 1577000 & 2,7 & Photosynth Toolkit \\
\hline \multirow{4}{*}{ 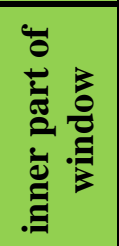 } & \multirow{4}{*}{14} & \multirow{4}{*}{$3-5 m$} & \multirow{4}{*}{5} & \multirow{4}{*}{$1 \mathrm{~mm}$} & 1779000 & 1,8 & PM Scanner \\
\hline & & & & & 1634000 & 0,5 & VisualSFM \\
\hline & & & & & 1498000 & 1,1 & OSM-Bundler \\
\hline & & & & & 1662000 & 1,5 & Photosynth Toolkit \\
\hline
\end{tabular}

${ }^{1}$ Ground Control Points

${ }^{2}$ Ground Sampling Distance - a pixel size expressed in ground (object space) units by reference to the image scale

${ }^{3}$ an overall mean error, indicates the accuracy in the reference system

\section{COMPARISON OF RESULTS}

Point clouds - sets of points defined by their spatial coordinates XYZ and radiometric data RGB are a result of the image processing of individual castle objects by three chosen software methods. As a first step, these outputs were compared with regard to the point cloud generated by PMSC in terms of point cloud consistency and photo-texture quality (Fig. 3).

Each of the software solutions provides different results to a certain extent, in terms of the point cloud consistency and the quality of reconstruction and photo-texture. VisualSFM and OSM-Bundler provide very similar results with minimal differences for all three objects, although the output from the VisualSFM software system contains more holes in the point cloud. On the other hand, Photosynth Toolkit generates the output with high quality photo-texture, but the point cloud contains a number of holes, isolated clusters of points and some parts of objects are completely missing (e.g. Fig. 3 - a wall of the Gothic palace).

Apart from the tested software methods, PMSC 2012 provides stable and high-quality results while respecting appropriate conditions of imaging and configuration of imaging stations (Fraštia, 2009). However, its major disadvantage is the fact that a point cloud is always generated only from a pair of images with approximately parallel image axes (although the newest version of PMSC includes the Multi-View Stereo DSM system), which may result in high noise and multiple faulty correlations between images. This fact is also one of the essential differences between the method of optical scanning (PMSC 2012) and the SfM method (VisualSFM, etc.). 
Other important aspects, by which we can assess the suitability and usability of open-source and free photogrammetric software, include their controllability, speed and potential future development. The VisualSFM software, whose development is advancing continuously and whose author works on its gradual improvement, troubleshooting and adding new functions and features, appears to be the most suitable of all three software methods. It also provides sufficiently detailed settings of processing parameters and calibration, relatively high processing speed (depending on hardware), reliability and a simple GUI. In contrast, OSM-Bundler and Photosynth Toolkit require additional libraries to be run, basic knowledge of the Windows command prompt, and their potential future development is questionable, since the current versions of both pieces of software come from the year 2010 (although for individual included algorithms, like PMVS, newer versions from different authors are still coming out).
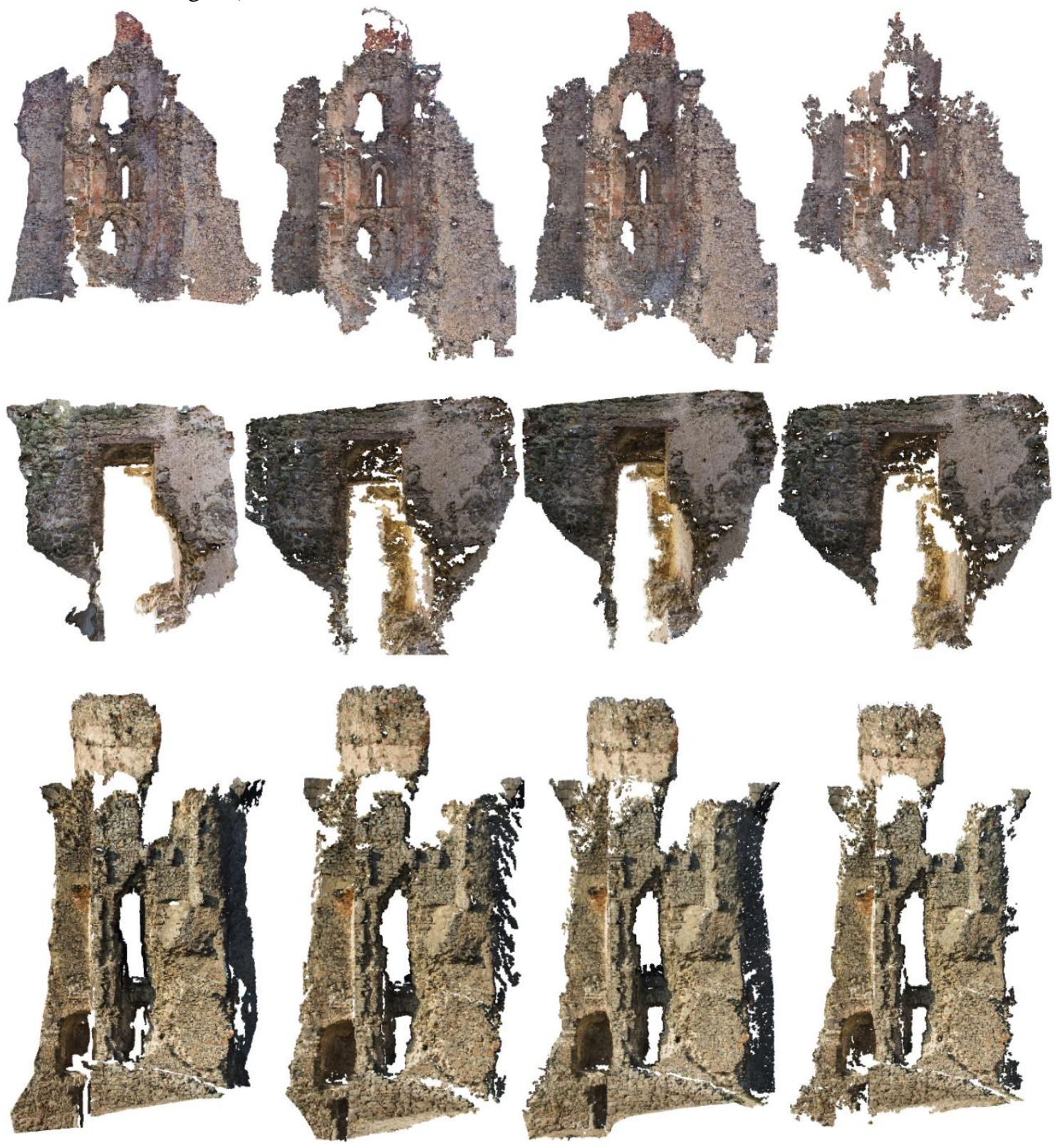

Fig. 3 The preview of the final point clouds of individual castle objects; from the left - PM Scanner, VisualSFM, OSM-Bundler, Photosynth Toolkit

As a second step, individual outputs were compared by means of relative distances and deviations between the compared point cloud and the point cloud from PMSC 2012 (Tab. 2). At first, the registration of the compared cloud with regard to the reference cloud was performed by applying the ICP algorithm (Iterative Closest Point) (Wild, 2010). Subsequently, values of maximum and mean distances between the clouds were determined by applying a local approximation of point cloud by a height function, using the CloudCompare software (Giradeau-Montaut et al., 2012). 
Tab. 2: The comparison of the tested software methods with respect to PMSC through mutual distances

\begin{tabular}{|c|c|c|c|c|c|}
\hline & $\begin{array}{c}R M S_{r e g}{ }^{I} \\
{[\mathrm{~mm}]} \\
\end{array}$ & $\begin{array}{c}\sigma^{2} \\
{[\mathrm{~mm}]}\end{array}$ & $\begin{array}{c}d_{m}^{3} \\
{[\mathrm{~mm}]}\end{array}$ & $\begin{array}{l}d_{\max }^{4} \\
{[\mathrm{~mm}]}\end{array}$ & \\
\hline \multirow{3}{*}{ 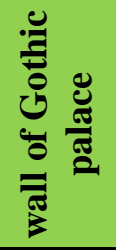 } & 6,3 & 2,8 & 2,0 & 39,9 & VisualSFM \\
\hline & 7,8 & 4,2 & 4,0 & 53,4 & OSM-Bundler \\
\hline & 6,1 & 2,9 & 2,3 & 56,4 & Photosynth Toolkit \\
\hline \multirow{3}{*}{ 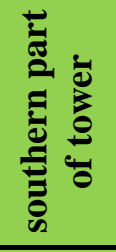 } & 4,5 & 2,4 & 2,3 & 29,4 & VisualSFM \\
\hline & 6,6 & 2,9 & 2,3 & 39,4 & OSM-Bundler \\
\hline & 7,6 & 3,7 & 3,1 & 46,2 & Photosynth Toolkit \\
\hline \multirow{3}{*}{ 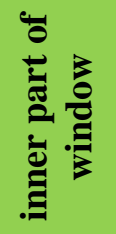 } & 3,7 & 1,7 & 1,1 & 32,2 & VisualSFM \\
\hline & 6,9 & 2,5 & 2,0 & 37,3 & oSM-Bundler \\
\hline & 4,5 & 1,9 & 1,2 & 68,7 & Photosynth Toolkit \\
\hline
\end{tabular}

The parts of the table highlighted in blue represent the lowest values and parts highlighted in red the highest values achieved. Making this comparison, Photosynth Toolkit produces on average the highest deviations and in the case of the wall of the Gothic palace it is OSM-Bundler (mean or maximum distances). Conversely, the lowest deviations for all three objects are produced by VisualSFM (for the inner part of the window $1.1 \mathrm{~mm}$ only), which thus appears to be the most suitable also on the basis of this comparison.

However, it is important to note that although the final outputs from each software methods (tested and PMSC 2012) are the same (point clouds), the methods of their generation are different (SfM vs. optical scanning). Since the point clouds created by optical scanning through PMSC 2012 might not always be of better quality and more accurate than the point clouds created by the SfM method (the method of their creation indicates rather the opposite), thus this type comparison would be more suitable if the reference data were obtained either by the same method, or by different technology (e.g. terrestrial laser scanning).

\section{CONCLUSION}

Results of this work indicates that each of the three tested software methods utilizing the SfM algorithms provides different results whether in the quality of reconstruction and photo-texture, or in the degree of deviations from a reference data. The OSM-Bundler and Photosynth Toolkit software methods provide relatively good and quality results, but their reliability is poor, which might be caused by the fact that they determine a specific set of interior orientation parameters for each used image, leading to unstable results. VisualSFM appears to be the most suitable open-source software, since it provides the possibility of fixed calibration, detailed settings of parameters affecting the reconstruction, and reliable results when compared to other tested software. Additionally, it provided the smallest deviations (on average) from the reference model over individual steps of testing.

Of course, it is always important to take into account the required quality of data for documentation of cultural heritage. For example, different accuracy and type of outputs and documentation will be required for the assessment of object's statics (more emphasis on accuracy) as for architectural and historical research (more emphasis on texture quality). Thus the question arises whether the comparison using mutual relative distances and deviations between point clouds (Table 2) is relevant in the case of using open-source or free photogrammetric software for the needs of cultural heritage documentation, for example castle ruins where the 
accuracy in $\mathrm{mm}$ does not play such an important role. However, it would be different in the case of shorter camera-to-object distances, for example reconstruction of objects small in size with rugged surface, archaeological findings, etc.

Finally, we can say that open-source and free photogrammetric software tools belong to current trends in photogrammetry. The current state of the art $S f M$ algorithms began to achieve the quality of commercial photogrammetric software and even in some cases they have already achieved it. However, a more detailed analysis of individual processing steps and calibration should be realized before their using in professional applications.

\section{REFERENCES}

[1] ASTRE, H. Photosynth Toolkit [computer software]. Ver. 11. 2010 [online]. Available at http://www.visual-experiments.com/demos/photosynthtoolkit/

[2] BARTOŠ, K. The use of open-source photogrammetric software for the needs of documentation of cultural heritage, its analysis and accuracy = Využitie open-source fotogrametrických softvérov pre potreby pamiatkovej dokumentácie, ich analýza a presnost'. PhD thesis. Košice: The Technical university of Košice, Faculty of mining, ecology, process control and geotechnology. 2013. 132 p.

[3] EOS SYSTEMS INC. Photomodeler Scanner. [computer software]. Published 2013. Available at http://www.photomodeler.com/products/scanner/default.html

[4] FRAŠTIA, M. Photogrammetry in the process of monuments documentation = Fotogrametria $v$ procese dokumentácie pamiatok. Bardkontakt 2009. Problematika mestských pamiatkových centier. Bardejov, 2009, City of Bardejov, ISBN 978-80-970188-9-4, pp. 30-35.

[5] FURUKAWA, Y. et al. Towards Internet-scale Multi-view Stereo. IEEE Conference on Computer Vision and Pattern Recognition. USA, San Francisco, 2010. pp. 1434-1441.

[6] FURUKAWA, Y. - PONCE, J. Accurate, Dense, and Robust Multi-View Stereopsis. IEEE Transactions On Pattern Analysis and Machine Intelligence. August 2010, Volume 32, Issue 8, pp. 1362-1376.

[7] GIRADEAU-MONTAUT, D. - BEY, A. - MARC, R. CloudCompare [computer software]. Ver. 2.4. 2012 [online]. Available at http://www.danielgm.net/cc/

[8] GRUEN, A. - BALTSAVIAS, E. Geometrically Constrained Multiphoto Matching. Photogrammetric Engineering \& Remote Sensing. Volume 54, pp. 633-641. 1988

[9] JANCOSEK, M. - PAJDLA, T. Multi-View Reconstruction Preserving Weakly-Supported Surfaces, CVPR 2011 - IEEE Conference on Computer Vision and Pattern Recognition, Colorado Springs, USA, 2011.

[10] KERSTEN, P. Thomas. 3D Point Clouds through Image-Based Low-Cost systems. CLGE General Assembly, Hannover, Germany, 2012.

[11] LABANT, S. et al. Processing of a geodetic network determined in ETRS-89 with application of different cofactors. In: Acta Montanistica Slovaca. Vol. 17, No. 1 (2012), pp. 9-16. - ISSN 1335-1788

[12] LOWE, G. David. Distinctive image features from scale-invariant keypoints. International Journal of Computer Vision [online] October, 2004, Volume 60, Number 1.

[13] MICROSOFT. Photosynth [web service]. USA, 2012 [online]. Available at http://photosynth.net/

[14] PIERROT-DESEILliGNY, M. - PAPARODITIS, N. A multiresolution and optimization-based image matching approach: an application to surface reconstruction from SPT5-HRS stereo imagery. Int. Archives of Photogrammetry, Remote Sensing and Spatial Information Sciences. Volume 36-1/W41. Ankara, Turkey, 2006.

[15] POLLEFEYS, M. et al. Visual modeling with a hand-held camera. International Journal of Computer Vision 59(3), 207-232, 2004.

[16] PUKANSKÁ, K. et al. Geodetic survey of the Slanec castle by laser scanning and photogrammetry = Geodetické zameranie Slaneckého hradu laserovým skenovaním a fotogrametricky. Final report. Košice: TU - 2012. - 28 p.

[17] SABO, J. - BÁLINT, J.: Possibilities of using GNSS in air navigation. In: New trends in civil aviation 2013. 21. - 22. June 2013, Žilina. - Brno: Akademické nakladatelství CERM, 2013 pp. 84-86. - ISBN 978-80-7204-843-4. 
[18] SNAVELY, N. Bundler [computer software]. USA, 2010 [online]. Available at http://phototour.cs.washington.edu/bundler/\#S3

[19] SNAVELY, N. et al. Photo Tourism: Exploring photo collections in 3D. ACM Transactions on Graphics (SIGGRAPH Proceedings). July, 2006, Volume 25 Issue 3. Pp. 835-846.

[20] WILD, M. Recent Development of the Iterative Closest Point (ICP) Algorithm. Swiss Federal Institute of Technology Zurich, 2010.

[21] WU, Ch. SiftGPU [computer software]. Ver. 400. USA, 2012 [online]. Available at http://www.cs.unc.edu/ ccwu/siftgpu/

[22] WU, Ch. VisualSFM [computer software]. Ver. 0.5.22. USA, 2013 [online]. Available at http://homes.cs.washington.edu/ ccwu/vsfm/ 